\title{
Biased Social Perceptions of Knowledge: Implications for Negotiators' Rapport and Egocentrism
}

\author{
David S. Lee, ${ }^{1}$ Scott J. Moeller, ${ }^{2}$ Shirli Kopelman, ${ }^{3}$ and Oscar Ybarra $^{1}$ \\ 1 Department of Psychology, University of Michigan, Ann Arbor, MI, U.S.A. \\ 2 Icahn School of Medicine at Mount Sinai, New York, NY, U.S.A. \\ 3 Ross School of Business, University of Michigan, Ann Arbor, MI, U.S.A.
}

\section{Keywords}

knowledge asymmetries, negotiation, rapport, egocentrism, social dilemmas.

\section{Correspondence}

David S. Lee, Department of Psychology, University of Michigan, 3221 East Hall, Ann Arbor, MI 48109, U.S.A.; e-mail: dsjlee@umich.edu. or

Oscar Ybarra, Department of Psychology, University of Michigan, 3006 East Hall, Ann Arbor, Ml 48109, U.S.A.; e-mail: oybarra@umich.edu.

\begin{abstract}
This study examines how people manage uncertain competitive social interactions. To achieve positive interaction outcomes, individuals may engage in a social perception process that leads them to believe they have obtained more information about others than these others gained about them. We investigate how asymmetric knowledge perceptions contribute to important aspects of negotiation, namely rapport building among strangers and egocentric beliefs about fairness of resource distribution. In Study 1, dyads completed measures of knowledge acquisition and partner evaluation after a rapport-building exercise. Results showed that individuals believed they gained more information about their partner than vice versa; notably, the magnitude of this knowledge bias was associated with more positive partner evaluations. Study 2 showed that the magnitude of the knowledge bias predicted lower egocentrism in a commons dilemma task. Together, these results suggest knowledge asymmetries facilitate rapport among strangers and may have important implications for cooperation in competitive negotiation settings.
\end{abstract}

Negotiation researchers have long been interested in how social relationship processes can facilitate positive negotiation outcomes (e.g., Greenhalgh \& Chapman, 1998; Rubin \& Brown, 1975; Valley, Neale, \& Mannix, 1995). However, what makes building rapport among negotiators challenging is that negotiation is a mixed-motive undertaking in which negotiators are motivated to cooperate with one another to reach an agreement but also simultaneously compete to claim resources (Kopelman, 2014; Lax \& Sebenius, 1986; Walton \& McKersie, 1965). Thus, negotiation contexts represent a social setting in which people deal with uncertainty - for example, not knowing the other's motives, the degree to which they are cooperative or competitive, whether they are trustworthy, or whether they are interested in building a long-term relationship.

The uncertainty inherent to negotiation contexts can pose a threat to one's sense of control over the social environment (cf. Berscheid, Graziano, Monson, \& Dermer, 1976) and produce anxiety (e.g., PageGould, Mendoza-Denton, \& Tropp, 2008; Rosette, Kopelman, \& Abbot, 2014; Stephan \& Stephan,

This research was supported by an institutional NRSA training grant fellowship. We thank Dong Lee and Meagan Mirtenbaum for assistance with data collection. We also thank Eugene Burnstein for helpful comments on an earlier version of this manuscript. 
1985). In addition, when people are uncertain about the interaction partner's intentions, they may be less inclined to reveal information about themselves to guard against possible exploitation (cf. Stephan \& Stephan, 1985). For example, when people expect to interact with a competitive (vs. cooperative) stranger, they prefer to be unpredictable, are less willing to open up, and are more willing to mislead the other (Rios, Ybarra, \& Sanchez-Burks, 2013; Ybarra et al., 2010). Because of the uncertainty, it is no surprise that negotiators tend to be egocentric (Thompson \& Loewenstein, 1992), overweighing views that favor themselves and interpreting fairness from their own point of view (Babcock \& Olson, 1992; Camerer \& Loewenstein, 1993; De Dreu \& McCusker, 1997; Diekmann, 1997; Messick \& Sentis, 1979).

Given the challenge of managing uncertainty inherent to many negotiation situations and keeping negotiations from sliding into purely distributive competitive interactions, it is important to determine the factors that influence the building of rapport - a critical factor to creating positive negotiation outcomes. Thus, the question we studied in this research is as follows: How do people mentally approach their interactions with unknown others to achieve more positive interactions and negotiation outcomes? This article investigated whether biased perceptions of knowledge acquisition (between self and other) could lead to positive evaluations of that person (Study 1), and whether the degree to which individuals displayed this tendency influenced beliefs about fair distribution of resources in negotiations (Study 2).

Relationships help people attain resources that would otherwise remain elusive and meet fundamental needs that would otherwise go unfulfilled (Axelrod \& Hamilton, 1981; Baumeister \& Leary, 1995; Bowlby, 1969; Deci \& Ryan, 2000; Maslow, 1968). Thus, people are generally motivated to develop friendships with others, many times in the service of establishing reciprocal relationships (Trivers, 1971). Although relationships are central to the human survival strategy, a fundamental question persists about how smooth interactions and negotiations among strangers unfold when uncertainty, wariness, and the possibility of exploitation loom in their minds. This matter becomes particularly problematic when people feel exposed to others with whom long-term social connection is uncertain, for example, a meeting or negotiation between strangers (Clark \& Chrisman, 1994; Loewenstein, Thompson, \& Bazerman, 1989; Stephan \& Stephan, 1985; Ybarra, 2002).

Potentially related to the above conundrum social actors face wanting relationships but seeking to protect the self are findings indicating that people express a pervasive motive to obtain information about their social worlds (Dunning, 2001; Ybarra, 2002) and reduce social uncertainty (Berger \& Calabrese, 1975). Thus, one psychological process that may help in managing uncertain social interactions - such as interactions involving strangers or unknown parties in a negotiation - and make them unfold more smoothly could involve people believing they have obtained information about others during interaction. Some research has shown, for example, that information sharing among team members can enhance group cohesion and performance (for a review, see Mesmer-Magnus \& DeChurch, 2009). Other research indicates that people like others who have disclosed to them (Berg \& Archer, 1983; Collins \& Miller, 1994; Mikulincer \& Nachshon, 1991; Vittengl \& Holt, 2000). But an independent process that may be masked in these studies is individuals' concerns with sharing too much information about themselves in uncertain social interactions.

Thus, in addition to being motivated to gain an understanding about others, and even being compelled to reciprocate disclosures, individuals may nevertheless seek to limit how much the other parties learn about them to reduce the chances of exploitation (Rios et al., 2013; Ybarra et al., 2010). This has implications for the evaluation of others, as interacting with strangers involves uncertainty (e.g., about that person's character and intentions), which is associated with reduced interpersonal control and negative interpersonal attitudes (e.g., Stephan \& Stephan, 1985; Tropp \& Pettigrew, 2005; Turner, Crisp, \& Lambert, 2007). Therefore, assessments of how much information a person believes they have gained in an interaction are important to consider with regard to the same individual's perceptions about what the other party learned about them, controlling for level of mutual disclosure.

Beliefs about knowledge gained by the self versus other can be conceptualized as an asymmetry. Research has shown, for example, that the knowledge perception process tends to be biased in favor of 
the actor. For example, work on the illusion of asymmetric insight suggests that people often believe they have gained more information about an interaction partner than that partner has gained about the self (Park, Choi, \& Cho, 2006; Pronin, Gilovich, \& Ross, 2004; Pronin, Kruger, Savtisky, \& Ross, 2001). None of the research on the illusion of asymmetric insight, however, has examined the knowledge asymmetry in relation to interpersonal and negotiation outcomes. How would a bias in knowledge perceptions that favors the self influence negotiations?

We propose that, beyond perceptions of mutual disclosure, people can manage the uncertainty of interacting with strangers by forming the belief that they have obtained more information about others than those others have gained about themselves (the self). Believing that one has gained information about others would allow perceivers to create a richer representation of these individuals (Swann \& Gill, 1997) and better simulate the interaction (Crisp \& Turner, 2009), processes associated with increased interpersonal confidence and positive perceptions of others. At the same time, people want to limit exposure during uncertain encounters (Ybarra et al., 2010), as overexposure can lead to anxiety (Jellison \& Ickes, 1974), reduced interpersonal control, and negative interpersonal attitudes (e.g., Stephan \& Stephan, 1985; Tropp \& Pettigrew, 2005; Turner et al., 2007). Taken together, positive interpersonal outcomes would occur to the extent that people believe they have more information about their partner than their partner has of them. In this research, we test this hypothesis that the magnitude of the illusion of asymmetric insight predicts positive interpersonal outcomes (Study 1: more positive evaluations of an interaction partner; Study 2: lower egocentrism during negotiations).

\section{Study 1}

Study 1 examined the process by which strangers meet for the first time and build rapport, an important phase of negotiations. Particularly, we tested whether evaluations of an interaction partner, after a brief rapport-building exercise, were enhanced as a function of the magnitude of the illusion of asymmetric insight. This illusion is defined from the individual's perspective, who is making judgments for both self and partner, and the degree to which individuals judge they obtained relatively more knowledge about their partner (actors' perceptions of knowledge about partner $=$ APK) than their partner obtained about them (actors' perceptions of partners' knowledge about the self = APPK). Two hypotheses guided Study 1: (a) An asymmetry in knowledge perception will emerge that favors the actor (i.e., APK will surpass APPK), replicating previous research (Park et al., 2006; Pronin et al., 2001, 2004). Of greater interest, we expected that (b) the higher the magnitude of the illusion, the more positive the partner evaluations. Further, and of critical importance, we expected that the effects of the illusion of asymmetric insight on partner evaluations would hold even when accounting for actors' perceptions of mutual disclosure between self and partner (actors' perception of mutual disclosure = APMD, more detail below). Finally, we expected the effects of the illusion of asymmetric insight on liking to hold even after controlling for emotion felt during the interaction, which could independently influence participants' ratings of their partner (Bodenhausen, 1993; Schwarz \& Clore, 2007; Urban \& Miller, 1998).

\section{Method}

\section{Participants and Procedure}

Previously unacquainted undergraduate dyads ( $N=54$ dyads; $57 \%$ females; age: $17-38$ [ $M=19.2] ; 62 \%$ Caucasian, 8\% African American, 17\% Asian or Asian American, 7\% Latino(a)) participated in a rapport-building exercise. This rapport-building task represented an uncertain social interaction because participants were strangers when the study commenced. Opposite-sex dyads were permitted, as gender composition of the dyads does not influence perceptions of knowledge acquisition between actor and partner (Clark et al., 2004; Pronin et al., 2001). 
After being introduced to the study, participants separately generated a list of questions to ask their partner, with instructions to "find out who [your partner] really is on the inside." Participants were asked to construct questions that would not (a) yield simple (e.g., yes or no) responses, (b) reveal personally identifying information, or (c) be perceived as intrusive, vulgar, or insensitive (no participant expressed concern about the questions posed to them). Participants then convened at a center table, where they each asked all their prepared questions in one block (i.e., they did not alternate at the conclusion of each question). Once the rapport-building exercise concluded, participants separately completed measures of perceived knowledge acquisition (for self about partner and what they thought the partner learned about them), partner evaluation, and positive and negative affects, described below.

Two variations of the procedure, pertaining to the number of questions generated and asked, were conducted. In the first variation, which included 21 dyads, participants generated eight questions, and then, they were randomly assigned to either ask all eight of their questions or only three of their eight questions (one member of each dyad asked eight questions, while the other member of the dyad asked three). In the second variation, which included the remaining 34 dyads, no experimental assignment occurred: Participants each generated and asked their partner five questions. Because the experimental manipulation conducted in the first variation did not impact APK, APPK, or partner evaluation $(F s<2.2, p s>.15)$, we collapsed data from these two procedures.

\section{Measures}

Perceived knowledge acquisition (APK) was assessed with eight items using a Likert-type scale, with values ranging from $1=$ not at all to $9=$ a great, great deal. The items were preceded by the following phrase: "How much do you think you know about your partner's..." These items included the following: "overall intelligence," "shyness in social situations," "sincerity or honesty," "political views," "aspirations or goals," "empathy toward other people," "knowledge of current events," and "conceptions of what he or she finds truly important" ( $\alpha=.77)$. Participants also answered the same set of questions, but they did so from the perspective of their interaction partner. These judgments served as an index of how much information participants perceived their partner gained about them (APPK). These items were preceded by the following phrase: "How much do you think your partner knows about your..." $(\alpha=.80)$. The order in which participants completed the measures of APK versus APPK was counterbalanced across sessions to preclude order effects (Schwarz, 1999). APK and APPK were positively correlated $(r=.69$, $p<.001)$.

Partner evaluation was assessed using a composite score of four items $(\alpha=.74)$, preceded by the following phrase: "To what extent do you think your partner is..." Items included "a nice person," "a friendly person," "someone with a lot of good qualities," and "someone you feel you can easily talk to." Participants responded using a response scale with values ranging from $1=$ not at all to $5=$ extremely.

Positive and negative affects were assessed separately with the Positive and Negative Affect Schedule (PANAS) (Watson, Clark, \& Tellegen, 1988) to account for the potentially confounding effect of emotion. Participants, using a scale from $1=$ not at all to $5=$ extremely, responded to 20 emotion adjectives (10 positive, e.g., excited, interested, $\alpha=.86 ; 10$ negative, e.g., upset, distressed, $\alpha=.80$ ) pertaining to how they felt during the interaction.

\section{Results}

Data analysis proceeded in three phases. Hierarchical linear modeling (HLM), conducted using the MIXED command in SPSS (IBM Corp., 2013), was used throughout all analyses to adjust for any bias in standard errors or statistical tests due to dyadic nonindependence (Kenny, Korchmaros, \& Bolger, 2003; Krull \& MacKinnon, 2001). Because participants within dyads were indistinguishable, we specified a compound symmetry covariance structure. 
In phase one of the analysis, we tested for potential differences in APK versus APPK, with the aim of replicating the illusion of asymmetric insight effect. In phase two, we examined the contribution of asymmetric APK to partner evaluation; in doing so, we sought to statistically account for APMD. Controlling for APMD in the analyses is crucial because perceived mutual disclosure (amount of information believed to be shared by self and other) has been shown to be a consistent predictor of partner evaluation and positive relationships (Berg \& Archer, 1983; Collins \& Miller, 1994; Mikulincer \& Nachshon, 1991; Vittengl \& Holt, 2000). To do this, we first computed the average of APK and APPK (yielding the variable APMD), which reflects the total amount of information believed to be exchanged between actor and partner, as reported by the actor. We then subtracted APMD from the original APK variable (yielding the variable asymmetric APK). This asymmetric APK variable reflects the amount of APK relative to the total amount of information exchanged. In phase three, we controlled for positive and negative affects. Table 1 presents the means and standard deviations for all variables.

Hierarchical linear modeling analysis revealed that APK surpassed APPK, $F(1,105.4)=13.80$, $p<.001$, consistent with an illusion of asymmetric insight effect. We then simultaneously entered APMD and asymmetric APK to predict partner evaluations (Figure 1A). HLM analysis confirmed that APMD was positively associated with partner evaluations, $B=0.16, S E=0.04, t(85.2)=4.33, p<.001$, indicating that the higher the perceived mutual disclosure between the participants, the more positive the partner evaluations. This finding is consistent with the self-disclosure literature and confirms the necessity to control for mutual disclosure in examining the present effects. Of greater interest, the HLM analysis revealed that asymmetric APK was also positively associated with partner evaluations, $B=0.23$, $S E=0.09, t(92.5)=2.68, p<.01$, indicating that the higher the perceived information gained by the participants relative to their partners, the more positive the partner evaluations. This effect of asymmetric APK on partner evaluations remained significant after controlling for positive affect, $B=0.24$, $S E=0.08, t(91.8)=2.92, p<.01$, and negative affect, $B=0.22, S E=0.09, t(91.7)=2.56, p<.05$.

\section{Discussion}

Study 1 tested the role that beliefs about information gained about an interaction partner, relative to the degree of information the partner was believed to have gained about the self, played in evaluations of

Table 1

Means and Standard Deviations of Variables Assessed in Studies 1 and 2

\begin{tabular}{lcc}
\hline Variable & $M$ & $S D$ \\
\hline Study 1 & & \\
APK & 4.00 & 1.44 \\
APPK & 3.58 & 1.45 \\
APMD & 3.79 & 1.32 \\
Asymmetric APK (APK-APMD) & 0.20 & 0.57 \\
Partner evaluation & 3.74 & 0.54 \\
Positive affect & 3.12 & 0.66 \\
Negative affect & 1.31 & 0.36 \\
Study 2 & & \\
APK & 4.22 & 1.11 \\
APPK & 4.18 & 1.20 \\
APMD & 4.20 & 1.11 \\
Asymmetric APK (APK-APMD) & 0.02 & 0.34 \\
Egocentrism (percent score) & 26.9 & 18.2 \\
\hline
\end{tabular}

Note. Egocentrism was subsequently z-scored by role for use in analyses.

APK, actors' perceived knowledge; APMD, actors' perceptions of mutual disclosure; APPK, actors' perceptions of partner knowledge. 
A

\section{Study 1}

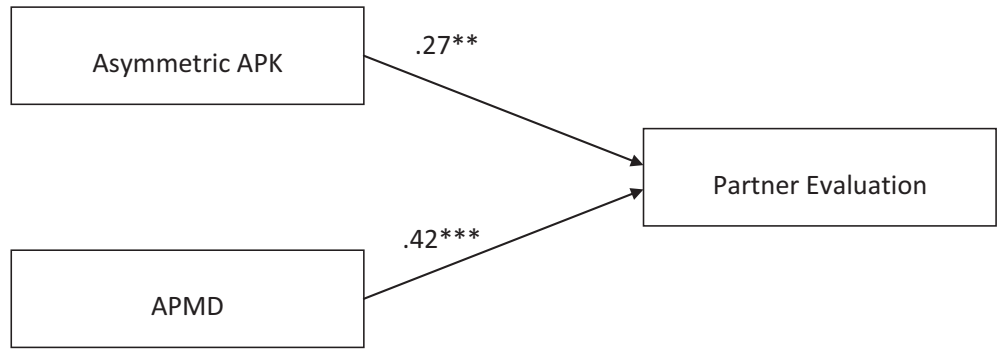

B

\section{Study 2}

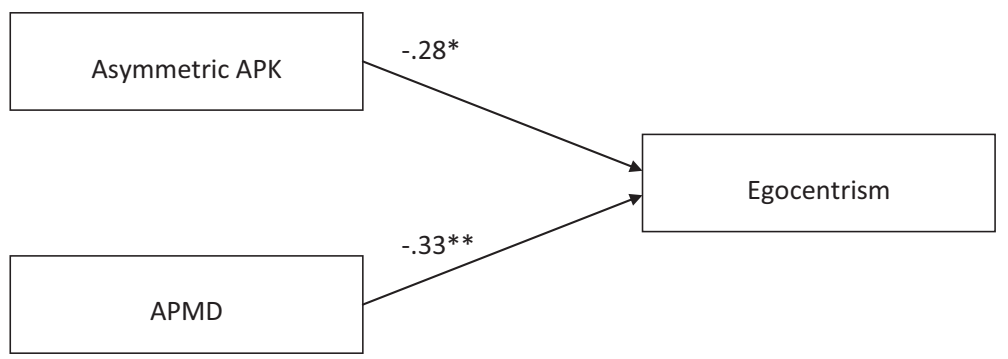

Figure 1. Prediction of partner evaluation (Study 1; A) and egocentrism (Study 2; B) by asymmetric actors' perceptions of knowledge (APK relative to actors' perceptions of partners' knowledge) and actors' perceptions of mutual disclosure (APMD). The figure shows partial correlations ascertained from multiple regression analyses that were adjusted for dyadic nonindependence $(* p<.05 ; * *<.01 ; * * * p<.001)$.

those interaction partners. Our first hypothesis was that an illusion of asymmetric knowledge acquisition that favors the actor would emerge as previously reported (Park et al., 2006; Pronin et al., 2001, 2004). Moreover, our second (and core) hypothesis was that the magnitude of this asymmetric insight (biased perception) would positively relate to partner evaluations.

Both hypotheses were supported. First, and consistent with the illusion of asymmetric insight effect, our results showed that APK surpassed APPK. Interestingly, this effect emerged despite our attempt to manipulate knowledge perception (by varying the amount of information exchanged between the interaction partners), potentially reflecting the robustness of the illusion of asymmetric insight when individuals meet each other. Second, our results showed that the magnitude of the illusion of asymmetric insight (asymmetric APK) was positively associated with partner evaluations. This effect of asymmetric APK cannot be attributed to emotion felt during the interaction, as additional analyses controlled for positive and negative affects. Further, although people tend to like those who reciprocate disclosure (Berg \& Archer, 1983; Collins \& Miller, 1994; Mikulincer \& Nachshon, 1991; Vittengl \& Holt, 2000), controlling for perceived mutual disclosure (APMD) did not preclude the effect of asymmetric APK. Thus, the amount of information that actors perceive they have obtained, relative to how much knowledge their partner is perceived to have gathered about the actors themselves (the self), accounts for variance in partner evaluations beyond that accounted for by perceptions of mutual disclosure. This outcome suggests that the illusion of asymmetric insight may represent a process that enables individuals to build rapport in uncertain social situations. 
However, it remains to be determined whether asymmetric APK influences what people believe to be fair resource distribution in uncertain social interactions. Study 2 investigated how the asymmetric APK relates to lower egocentrism when negotiating over scarce resources.

\section{Study 2}

Study 2 tested the hypothesis that asymmetric APK relates to less egocentrism during an uncertain, tacit group coordination task. The negotiation task used in Study 2 allowed us to examine the kinds of decisions people make during an uncertain social interaction where exploitation could occur (a commons dilemma) and also allowed us to extend our research question beyond dyads to small groups.

In a commons dilemma, interdependent decision-makers may tacitly negotiate to prevent complete depletion of a scarce resource (Hardin, 1968; Van Lange, Liebrand, Messick, \& Wilke, 1992). Commons dilemmas reflect tacit negotiations in which direct communication or binding contracts are either difficult to achieve or illegal, and therefore, it is highly plausible that implicit psychological processes influence such social interactions (Kopelman, 2009; Schelling, 1960; Thompson, 2001). Extensive research in social psychology and experimental economics highlights the importance of studying such implicit psychological processes, which have implications for management of sustainable resources on a global scale (Dawes, 1980; Komorita \& Parks, 1994; Kopelman, 2009; Kopelman, Weber, \& Messick, 2002; Messick \& Brewer, 1983).

Study 2 focused on egocentrism, the belief that a decision-maker deserves a larger portion of the common resource (Kopelman, 2009; Wade-Benzoni, Tenbrunsel, \& Bazerman, 1996). Lower egocentrism reflects an individual's willingness to sacrifice personal gain for the well-being of the group and the sustainability of the scarce resource. If asymmetric APK facilitates positive evaluations of others, and thus rapport, as suggested by Study 1, then those participants with high asymmetric APK would render less egocentric decisions because the possibility of exploitation is diminished. This perspective would align with past research indicating that positive evaluations can serve as a simple heuristic through which negotiators arrive at judgments (Neale \& Bazerman, 1991) and that negotiators do not necessarily make decisions based on their self-interest when negotiating with parties with whom they have high-quality (e.g., romantic) relationships (Valley et al., 1995). Therefore, in Study 2, we hypothesized that asymmetric APK would predict lower egocentrism with respect to the amount of resources people believe is fair for them to take for themselves or their constituents.

\section{Method}

\section{Participants and Procedure}

Masters of business administration students $(N=85 ; 36 \%$ females; age: $22-41[M=28.91, S D=3.54]$; work experience: $0-20$ years $[M=5.60, S D=3.32]$; 50\% Asian or Asian American, 35\% Caucasian, $6 \%$ Latino(a), 4\% African American, and 4\% other; seven of the 92 students were missing data and excluded from the analysis) participated in a four-person group asymmetric commons dilemma called Shark Harvesters and Resources Conservation (SHARC; Wade-Benzoni et al., 1996) as part of a class exercise on negotiation. Participants role-played one of four for-profit shark fishing associations. Two roles represented commercial fishermen (large commercial [LC] and small commercial [SC]), who had relatively high economic power, and two represented recreational fishermen (recreational competition $[\mathrm{RC}]$ and recreational tours $[\mathrm{RT}]$ ), who had relatively low economic power. Due to these economic power differences (economic power was defined as current market share and future dependence on the resource), this task is conceptualized to be an asymmetric commons dilemma. Asymmetric commons dilemmas are more prevalent than situations of economic power symmetry and are considered an ecologically valid 
(Murnighan, King, \& Schoumaker, 1990) depiction of real-world commons dilemmas (for a review, see Kopelman et al., 2002).

Participants received background materials that explained collective over-harvesting by the fishing industry (LC, SC, RC, and RT) was depleting the resource (shark) faster than it could replenish (reproduce). Sustainability of the resource required the industry to lower the overall harvest from the current collective harvest of 5,000 metric tons ( $\mathrm{LC}=2,000, \mathrm{SC}=1,500, \mathrm{RC}=1,000$, and $\mathrm{RT}=500$ ) to 2,500 metric tons. The common goal for all parties was to reduce collective harvesting, while the individual goal of each representative concerned protecting the economic well-being of his or her shark fishing association and its members. Participants were randomly assigned to the role of LC, SC, RC, or RT and randomly assigned to one of 23 groups. Participants were allotted 30 minutes to discuss the dilemma, during which no explicit agreements could be made regarding their intended harvest. Following this discussion, participants independently completed measures of knowledge perception and egocentrism. The SHARC task was then debriefed.

\section{Measures}

Perceived knowledge was assessed with the same knowledge items used in Study 1 but this time using 7point scales. Each item was preceded by the following phrase: "How much do you think you know about the other group members' (other members know about your) ..." Thus, in this study, participants reported on their perceptions of knowledge of the collective and their perceptions of the collective's knowledge of them. Participants completed these knowledge ratings online and separately from their group. As in Study 1 , we computed composites of APK $(\alpha=.86)$ and APPK $(\alpha=.90)$, which again were positively correlated $(r=.83, p<.001)$. From these variables, we also computed indices of APMD and asymmetric APK, following the procedures described for Study 1.

Egocentrism reflected the market share participants felt their fishing association deserved. Participants reported what they believed represented a fair harvest for their own association and for each of the other three associations. We calculated each association's egocentrism score by dividing the percentage they believed was fair for them to harvest by the total industry harvest they thought was fair. For example, if an LC representative believed a fair solution to the commons dilemma involved reducing LC's harvest to 1,500 , SC to 700 , RC to 200 , and RT to 100 , then the LC's egocentrism measure would be $1,500 /$ $(1,500+700+200+100)=1,500 / 2,500=60 \%$. Higher percentages signified higher egocentrism. Egocentrism percentage scores were standardized by role; therefore, the $z$-scores reflected egocentrism compared with other individuals assigned to represent the same association. Standardization was necessary due to economic power differences and, therefore, potential differences in perceptions of fairness among the roles.

\section{Results}

Table 1 presents the means and standard deviations for all Study 2 variables. HLM with a compound symmetry covariance structure was conducted to account for group nonindependence, with participants nested within their respective discussion group.

Study 2 analyses paralleled those for Study 1, with the exception that we did not assess positive or negative affect regarding the interaction. Although we did not observe the expected illusion of asymmetric insight effect (i.e., APK did not surpass APPK), $F(1,84.0)=0.26, p>.61$, our primary HLM analysis, in which APMD and asymmetric APK were entered as simultaneous predictors of egocentrism (Figure 1B), revealed a negative association between APMD and egocentrism, $B=-0.27, S E=0.09, t(69.9)=-2.96$, $p<.01$. This finding indicated that the higher the perceived mutual disclosure between participants and the collective, the lower the egocentrism displayed by the individual participants. And more pertinent to our hypotheses, this same HLM analysis revealed a negative association between asymmetric APK and 
egocentrism as predicted, $B=-0.60, S E=0.28, t(52.4)=-2.14, p<.05$. This latter finding indicated that the higher the perceived information gained by the participants relative to the collective, the lower the egocentrism of individual participants in their negotiation decisions.

\section{Discussion}

Consistent with our hypotheses, Study 2 results showed that asymmetric APK relates to less egocentrism during a tacit negotiation task, indicating that participants with high scores on this asymmetric APK variable were more likely to believe it would be fair to sacrifice their own self-interest for the collective interests of the group. Accordingly, the effect of asymmetric APK on task-related egocentrism extends the results of Study 1 and is consistent with previous research suggesting that knowledge about others decreases egocentric tendencies (Kruger, Windschitl, Burrus, Fessel, \& Chambers, 2008). Study 2 extended the results of Study 1 by showing that the relation between asymmetric APK and indicators of positive interactions (egocentrism in Study 2) also holds in small group negotiation settings and not only during dyadic interactions.

In general, the effect of asymmetric APK contributes to an emerging understanding of the psychological factors that enhance cooperation during commons dilemmas (Kopelman et al., 2002; Weber, Kopelman, \& Messick, 2004). Particularly, the finding that the asymmetric APK led to beliefs that it would be fair to forgo self-interest in negotiations for the good of the group is consistent with a growing body of research emphasizing the importance of relational capital (e.g., liking, trust, quality of dyadic relationship) among negotiating parties (De Clercq \& Sapienza, 2006; Gelfand, Major, Raver, Nishii, \& O'Brien, 2006). Our findings, for example, fit well with the idea of relational accomodation, whereby negotiators forfeit economic outcomes, either consciously or nonconsciously, to pursue relational goals and adhere to relational norms (Curhan, Neale, Ross, \& Rosencranz-Engelmann, 2008). Moreover, the results are particularly interesting in light of research suggesting that power reduces perspective-taking (Galinsky, Magee, Inesi, \& Gruenfeld, 2006; Mannix \& Neale, 1993). Ostensibly, reduced egocentrism necessitates adopting the perspective of others who also depend on the same resource. Thus, our study suggests that the perception of increased knowledge relative to others' knowledge, which can be construed as a form of illusory power, potentially enhanced a form of perspective-taking manifested as less egocentrism. Future research could examine whether APK instills feelings of power, not necessarily to control the outcomes of the interaction, but in terms of the power to understand others.

In Study 2, the effect of asymmetric APK emerged even without mean differences between APK and APPK. This latter nonsignificant effect may be attributable to the number of other group members. In contrast to Study 1, which consisted entirely of dyads, Study 2 participants were perceived by multiple others, which may have made it challenging for participants to conclude that they had obtained more information about the collective than the collective had obtained about them. It would be interesting for future research to experimentally manipulate the number of other group members and more systematically examine how being perceived by multiple others influences expression of this bias. Nevertheless, Study 2 supported our central prediction that asymmetric APK is associated with less egocentrism during a negotiation.

\section{General Discussion}

Two studies demonstrated that actors' perceived knowledge about interaction partners (APK) relative to their perceptions of their partners' knowledge gained about the self (APPK) is associated with positive interpersonal outcomes under conditions of uncertainty. Study 1 showed that when interacting with strangers, higher relative APK to APPK (asymmetric APK) was associated with more positive partner evaluations. Study 2 extended this finding by showing that when weighing self-interest against a higherorder group goal in a negotiation, higher asymmetric APK was associated with lower egocentrism about 
what would be a fair distribution of resources. These findings collectively suggest that perceptions of knowledge about others may reduce uncertainty during interactions and alleviate the belief that exploitation could occur (assuming this knowledge is not negative), affording people perceptions of control over their environments, even if such perceptions are not necessarily warranted (Langer, 1975; Thompson, Armstrong, \& Thomas, 1998).

Our findings may also speak to the functionality of the illusion of asymmetric insight, insofar as this egocentric bias can have practical consequences for interpersonal relationships. Previous research has uncovered how this bias is expressed, but not why it is expressed (Pronin et al., 2001, 2004). The present findings build on prior research and suggest that this asymmetry may have its roots in the establishment of interpersonal relationships, particularly among strangers and uncertain others.

The present studies are not without their limitations. First, the studies relied on correlation analyses, raising the possibility of alternative causal sequences. For example, people who initially like one another may communicate better, elevating both the perceptions of knowledge exchange and the resulting group cooperation (Bouas \& Komorita, 1996; Dawes, McTavish, \& Shaklee, 1977; Dawes, van de Kragt, \& Orbell, 1990; Kerr \& Kaufman-Gilliland, 1994; Kopelman et al., 2002; Weber et al., 2004). Nevertheless, in both studies, we included the APMD to statistically account for the potentially confounding influence of high mutual disclosure. Second, while the asymmetric insight favoring the self reduces uncertainty about an imminent interaction in theory, the present studies did not assess variables that may explain the asymmetry effect. It would be fruitful for future research to investigate the role of potential mediating constructs such as trust, control, power, or empathy (Andreoni \& Rao, 2011; Galinsky et al., 2006; Thompson et al., 1998) that may further explain the asymmetry effect. Third, we acknowledge the potential impact on the results of subtle interaction variables that were not assessed in the present studies, including nonverbal behavior (Ambady \& Rosenthal, 1993; Choi, Gray, \& Ambady, 2005; Gilbert \& Krull, 1988) and eye contact (Bond, Kahler, \& Paolicelli, 1985; Iizuka, 1992). How they may relate to the significant effects of asymmetric APK offers a direction for future research.

A theoretically intriguing interpretation of our findings is that participants may have followed a logic of appropriateness - what does a person like me (identity) do (rules) in a situation like this (recognition) given this culture (group)? - to inform the degree to which they thought it would be fair to cooperate (Arora, Peterson, Krantz, Hardisty, \& Reddy, 2012; Kopelman, 2009; March, 1994; Weber et al., 2004). Specifically, it is possible that while interacting with others, they perceived their identity (e.g., as more relational) or recognized the situation (e.g., benign, less threatening; long term vs. short term) differently, prompting them to be less egocentric when facing a social dilemma. Specifically, asymmetric APK may have prompted or afforded participants the capacity to view their identity, the rules for resource distribution, the situation, or the anticipated group culture differently, although the present studies did not measure these factors. Furthermore, we may not be able to generalize our findings to interactions or relationships that extend over time, as our data included one-shot interactions. The relation between actors' knowledge perceptions and partner evaluation may plateau or possibly even reverse with time (Norton, Frost, \& Ariely, 2007). In a similar vein, over time, knowledge perception favoring the self may lead to overconfidence, which can be detrimental to relationships (e.g., Bushman \& Baumeister, 1998; Campbell, Foster, \& Finkel, 2002). Examining perceptions of knowledge and how they may impact longer-term relationships and negotiations would be an interesting direction for future research.

In summary, the present studies are consistent with the idea that asymmetric knowledge perceptions shape evaluations of interaction partners and beliefs about fair resource distribution. Our findings help elucidate the question of how people interact and make decisions during uncertain interactions. People navigate a complex social world that necessitates interaction and negotiation with others, but the possibility of exploitation persistently looms. To facilitate an uncertain interaction, people may generate the belief, whether consciously or unconsciously, that they have an informational advantage over others. 
Insofar as this belief reduces social uncertainty, asymmetric perceptions of knowledge about others may constitute adaptive cognitive tools that help people manage interactions, helping competitive dynamics unfold cooperatively to attain better outcomes.

\section{References}

Ambady, N., \& Rosenthal, R. (1993). Half a minute: Predicting teacher evaluations from thin slices of nonverbal behavior and physical attractiveness. Journal of Personality and Social Psychology, 64, 431-441. doi:10.1037/ 0022-3514.64.3.431

Andreoni, J., \& Rao, J. M. (2011). The power of asking: How communication affects selfishness, empathy, and altruism. Journal of Public Economics, 95, 513-520. doi:10.1016/j.jpubeco.2010.12.008

Arora, P., Peterson, N. D., Krantz, D. H., Hardisty, D. J., \& Reddy, K. S. (2012). To cooperate or not to cooperate: Using new methodologies and frameworks to understand how affiliation influences cooperation in the present and future. Journal of Economic Psychology, 33, 842-853. doi:10.1016/j.joep.2012.02.006

Axelrod, R., \& Hamilton, W. D. (1981). The evolution of cooperation. Science, 211, 1390-1396. doi:10.1126/science.7466396

Babcock, L. C., \& Olson, C. A. (1992). The causes of impasses in labor disputes. Industrial Relations: A Journal of Economy and Society, 31, 348-360. doi:10.1111/j.1468-232X.1992.tb00313.x

Baumeister, R. F., \& Leary, M. R. (1995). The need to belong: Desire for interpersonal attachments as a fundamental human motivation. Psychological Bulletin, 117, 497-529. doi:10.1037/0033-2909.117.3.497

Berg, J. H., \& Archer, R. L. (1983). The disclosure-liking relationship: Effects of self-perception, order of disclosure, and topical similarity. Human Communication Research, 10, 269-281. doi:10.1111/j.1468-

2958.1983.tb00016.x

Berger, C. R., \& Calabrese, R. J. (1975). Some explorations in initial interaction and beyond: Toward a developmental theory of interpersonal communication. Human Communication Research, 1, 99-112. doi:10.1111/ j.1468-2958.1975.tb00258.x

Berscheid, E., Graziano, W., Monson, T., \& Dermer, M. (1976). Outcome dependency: Attention, attribution, and attraction. Journal of Personality and Social Psychology, 34, 978-989. doi:10.1037//0022-3514.34.5.978

Bodenhausen, G. V. (1993). Emotions, arousal, and stereotypic judgments: A heuristic model of affect and stereotyping. In D. M. Mackie \& D. L. Hamilton (Eds.), Affect, cognition, and stereotyping: Interactive processes in group perception (pp. 13-37). San Diego, CA: Academic Press.

Bond, C. F., Kahler, K. N., \& Paolicelli, L. M. (1985). The miscommunication of deception: An adaptive perspective. Journal of Experimental Social Psychology, 21, 331-345. doi:10.1016/0022-1031(85)90034-4

Bouas, K. S., \& Komorita, S. S. (1996). Group discussion and cooperation in social dilemmas. Personality and Social Psychology Bulletin, 22, 1144-1150. doi:10.1177/01461672962211005

Bowlby, J. (1969). Attachment and Loss: Vol 1. Attachment. New York, NY: Basic Books.

Bushman, B. J., \& Baumeister, R. F. (1998). Threatened egotism, narcissism, self-esteem, and direct and displaced aggression: Does self-love or self-hate lead to violence? Journal of Personality and Social Psychology, 75(1), 219229. doi:10.1037/0022-3514.75.1.219

Camerer, C., \& Loewenstein, G. (1993). Information, fairness, and efficiency in bargaining. In B. A. Mellers \& J. Baron (Eds.), Psychological perspectives on justice: Theory and applications (pp. 155-179). New York, NY: Cambridge University Press.

Campbell, W. K., Foster, C. A., \& Finkel, E. J. (2002). Does self-love lead to love for others? A story of narcissistic game playing. Journal of Personality and Social Psychology, 83, 340-354. doi:10.1037/0022-3514.83.2.340

Choi, V. S., Gray, H. M., \& Ambady, N. (2005). The glimpsed world: Unintended communication and unintended perception. In R. R. Hassin, J. S. Uleman, \& J. A. Bargh (Eds.), The new unconscious (pp. 309-333). New York, NY: Oxford University Press.

Clark, M. S., \& Chrisman, K. (1994). Resource allocation in intimate relationships. In M. J. Lerner \& G. Mikula (Eds.), Entitlement and the affectional bond (pp. 65-88). New York: Springer-Verlag. 
Clark, R. A., Dockum, M., Hazeu, H., Huang, M., Luo, N., Ramsey, J., et al. (2004). Initial encounters of young men and women: Impressions and disclosure estimates. Sex Roles, 50, 699-709. doi:10.1023/B: SERS.0000027571.75455.e1

Collins, N. L., \& Miller, L. C. (1994). Self-disclosure and liking: A meta-analytic review. Psychological Bulletin, 116, 457-475. doi:10.1037//0033-2909.116.3.457

Crisp, R. J., \& Turner, R. N. (2009). Can imagined interactions produce positive perceptions? Reducing prejudice through simulated social contact. American Psychologist, 64, 231-240. doi:10.1037/a0014718

Curhan, J. R., Neale, M. A., Ross, L., \& Rosencranz-Engelmann, J. (2008). Relational accommodation in negotiation: Effects of egalitarianism and gender on economic efficiency and relational capital. Organizational Behavior and Human Decision Processes, 107, 192-205. doi:10.1016/j.obhdp.2008.02.009

Dawes, R. M. (1980). Social dilemmas. Annual Review of Psychology, 31, 169-193. doi:10.1146/annurev.ps.31.020180.001125

Dawes, R. M., McTavish, J., \& Shaklee, H. (1977). Behavior, communication, and assumptions about other people's behavior in a commons dilemma situation. Journal of Personality and Social Psychology, 35, 1-11. doi:10.1037//0022-3514.35.1.1

Dawes, R. M., van de Kragt, A. J. C., \& Orbell, J. M. (1990). Cooperation for the benefit of us-Not me, or my conscience. In J. J. Mansbridge (Ed.), Beyond self-interest (pp. 97-110). Chicago, IL: University of Chicago Press.

De Clercq, D., \& Sapienza, H. J. (2006). Effects of relational capital and commitment on venture capitalists' perception of portfolio company performance. Journal of Business Venturing, 21, 326-347. doi:10.1016/j.jbusvent.2005.04.007

De Dreu, C. K., \& McCusker, C. (1997). Gain-loss frames and cooperation in two-person social dilemmas: A transformational analysis. Journal of Personality and Social Psychology, 72, 1093-1106. doi:10.1037//00223514.72.5.1093

Deci, E. L., \& Ryan, R. M. (2000). The 'what' and 'why' of goal pursuits: Human needs and the self-determination of behavior. Psychological Inquiry, 11, 227-268. doi:10.1207/S15327965PLI1104_01

Diekmann, K. A. (1997). 'Implicit justifications' and self-serving group allocations. Journal of Organizational Behavior, 18, 3-16. doi:10.1002/(SICI)1099-1379(199701)18:1<3:AID-JOB793>3.0.CO;2-D

Dunning, D. (2001). On the motives underlying social cognition. In A. Tesser \& N. Schwarz (Eds.), Blackwell handbook of social psychology: Intraindividual processes (pp. 348-374). Oxford, UK: Blackwell.

Galinsky, A. D., Magee, J. C., Inesi, M. E., \& Gruenfeld, D. H. (2006). Power and perspectives not taken. Psychological Science, 17, 1068-1074. doi:10.1111/j.1467-9280.2006.01824.x

Gelfand, M. J., Major, V. S., Raver, J. L., Nishii, L. H., \& O’Brien, K. (2006). Negotiating relationally: The dynamics of the relational self in negotiations. Academy of Management Review, 31, 427-451. doi:10.5465/ AMR.2006.20208689

Gilbert, D. T., \& Krull, D. S. (1988). Seeing less and knowing more: The benefits of perceptual ignorance. Journal of Personality and Social Psychology, 54, 193-202. doi:10.1037//0022-3514.54.2.193

Greenhalgh, L., \& Chapman, D. I. (1998). Negotiator relationships: Construct measurement, and demonstration of their impact on the process and outcomes of negotiation. Group Decision and Negotiation, 7, 465-489. doi:10.1023/A:1008694307035

Hardin, G. (1968). The tragedy of the commons. Science, 162, 1243-1248. doi:10.1080/19390450903037302

IBM Corp. (2013). IBM SPSS statistics for Windows, Version 22.0. Armonk, NY: IBM Copr.

Iizuka, Y. (1992). Evaluation of gaze pairs by female observers. Japanese Journal of Experimental Social Psychology, 31, 231-239. doi:10.2130/jjesp.31.231

Jellison, J. M., \& Ickes, W. J. (1974). The power of the glance: Desire to see and be seen in cooperative and competitive situations. Journal of Experimental Social Psychology, 10, 444-450. doi:10.1016/0022-1031(74) 90012-2

Kenny, D. A., Korchmaros, J. D., \& Bolger, N. (2003). Lower level mediation in multilevel models. Psychological Methods, 8, 115-128. doi:10.1037/1082-989X.8.2.115

Kerr, N. L., \& Kaufman-Gilliland, C. M. (1994). Communication, commitment, and cooperation in social dilemma. Journal of Personality and Social Psychology, 66, 513-529. doi:10.1037//0022-3514.66.3.513

Komorita, S. S., \& Parks, C. D. (1994). Social dilemmas. Boulder, CO: Westview Press. 
Kopelman, S. (2009). The effect of culture and power on cooperation in commons dilemmas: Implications for global resource management. Organizational Behavior and Human Decision Processes, 108, 153-163. doi:10.1016/j.obhdp.2008.06.004

Kopelman, S. (2014). Negotiating genuinely: Being yourself in business. Stanford, CA: Stanford University Press.

Kopelman, S., Weber, J. M., \& Messick, D. M. (2002). Factors influencing cooperation in commons dilemmas: A review of experimental psychological research. In E. Ostrom, T. Dietz, N. Dolsak, P. C. Stern, S. Sonich, \& E. U. Weber (Eds.), The drama of the commons (pp. 113-156). Washington, DC: National Academy Press.

Kruger, J., Windschitl, P. D., Burrus, J., Fessel, F., \& Chambers, J. R. (2008). The rational side of egocentrism in social comparisons. Journal of Experimental Social Psychology, 44, 220-232. doi:10.1016/j.jesp.2007.04.001

Krull, J. L., \& MacKinnon, D. P. (2001). Multilevel modeling of individual and group level mediated effects. Multivariate Behavioral Research, 30, 41-62. doi:10.1207/S15327906MBR3602_06

Langer, E. J. (1975). The illusion of control. Journal of Personality and Social Psychology, 32, 311-328. doi:10.1037//0022-3514.32.2.311

Lax, D. A., \& Sebenius, J. K. (1986). The managerial negotiator: Bargaining for cooperation and competitive gain. New York, NY: Free Press.

Loewenstein, G. F., Thompson, L., \& Bazerman, M. H. (1989). Social utility and decision making in interpersonal contexts. Journal of Personality and Social Psychology, 57, 426-441. doi:10.1037/0022-3514.57.3.426

Mannix, E. A., \& Neale, M. A. (1993). Power imbalance and the pattern of exchange in dyadic negotiation. Group Decision and Negotiation, 2, 119-133. doi:10.1007/BF01884767

March, J. (1994). A primer on decision-making: How decisions happen. New York, NY: Free Press.

Maslow, A. H. (1968). Motivation and personality. New York, NY: Harper \& Row.

Mesmer-Magnus, J. R., \& DeChurch, L. A. (2009). Information sharing and team performance: A meta-analysis. Journal of Applied Psychology, 94, 535-546. doi:10.1037/a0013773

Messick, D. M., \& Brewer, M. (1983). Solving social dilemmas: A review. In L. Wheeler \& P. R. Shaver (Eds.), Review of personality and social psychology (Vol. 4, pp. 11-44). Beverly Hills, CA: Sage.

Messick, D. M., \& Sentis, K. P. (1979). Fairness and preference. Journal of Experimental Social Psychology, 15, 418434. doi:10.1016/0022-1031(79)90047-7

Mikulincer, M., \& Nachshon, O. (1991). Attachment styles and patterns of self-disclosure. Journal of Personality and Social Psychology, 61, 321-331. doi:10.1037//0022-3514.61.2.321

Murnighan, J. K., King, T. R., \& Schoumaker, F. (1990). The dynamics of cooperation in asymmetric dilemmas. In E. Lawler (Ed.), Advances in Group Processes (Vol. 7, pp. 179-202). Greenwich, CT: JAI Press.

Neale, M. A., \& Bazerman, M. H. (1991). Cognition and rationality in negotiation. New York, NY: Free Press.

Norton, M. I., Frost, J. H., \& Ariely, D. (2007). Less is more: The lure of ambiguity, or why familiarity breeds contempt. Journal of Personality and Social Psychology, 92, 97-105. doi:10.1037/0022-3514.92.1.97

Page-Gould, E., Mendoza-Denton, R., \& Tropp, L. R. (2008). With a little help from my cross-group friend: Reducing anxiety in intergroup contexts through cross-group friendship. Journal of Personality and Social Psychology, 95, 1080-1094. doi:10.1037/0022-3514.95.5.1080

Park, J., Choi, I., \& Cho, G. (2006). The actor-observer bias in beliefs of interpersonal insights. Journal of CrossCultural Psychology, 37, 630-642. doi:10.1177/0022022106290482

Pronin, E., Gilovich, T., \& Ross, L. (2004). Objectivity in the eye of the beholder: Divergent perceptions of bias in self versus others. Psychological Review, 111, 781-799. doi:10.1037/0033-295X.111.3.781

Pronin, E., Kruger, J., Savtisky, K., \& Ross, L. (2001). You don't know me, but I know you: The illusion of asymmetric insight. Journal of Personality and Social Psychology, 81, 639-656. doi:10.1037/0033-295X.111.3.781

Rios, K., Ybarra, O., \& Sanchez-Burks, J. (2013). Outgroup primes induce unpredictability tendencies in people. Journal of Experimental Social Psychology, 49, 372-377. doi:10.1016/j.jesp.2012.12.014

Rosette, A., Kopelman, S., \& Abbot, J. L. (2014). Good grief! Feeling of anxiety sour the economic benefits of first offers. Group Decision and Negotiation, 23, 629-647. doi:10.1007/s10726-013-9348-4

Rubin, J. Z., \& Brown, B. R. (1975). The social psychology of bargaining and negotiation. New York, NY: Academic Press.

Schelling, T. C. (1960). The strategy of conflict. Oxford, UK: Harvard University Press. 
Schwarz, N. (1999). Self-reports: How the questions shape the answers. American Psychologist, 54, 93-105. doi:10.1037//0003-066X.54.2.93

Schwarz, N., \& Clore, G. L. (2007). Feelings and phenomenal experiences. In A. Kruglanski \& E. T. Higgins (Eds.), Social psychology. Handbook of basic principles (2nd ed., pp. 385-407). New York, NY: Guilford.

Stephan, W. G., \& Stephan, C. W. (1985). Intergroup anxiety. Journal of Social Issues, 41, 157-175. doi:10.1111/ j.1540-4560.1985.tb01134.x

Swann, W. B., \& Gill, M. J. (1997). Confidence and accuracy in person perception: Do we know what we think we know about our relationship partners? Journal of Personality and Social Psychology, 73, 747-757. doi:10.1037// 0022-3514.73.4.747

Thompson, L. (2001). The mind and heart of the negotiator (2nd ed.). Upper Saddle River, NJ: Prentice Hall.

Thompson, S. C., Armstrong, W., \& Thomas, C. (1998). Illusions of control, underestimations, and accuracy: A control heuristic explanation. Psychological Bulletin, 123, 143-161. doi:10.1037//0033-2909.123.2.143

Thompson, L., \& Loewenstein, G. (1992). Egocentric interpretations of fairness and interpersonal conflict. Organizational Behavior and Human Decision Processes, 51, 176-197. doi:10.1016/0749-5978(92)90010-5

Trivers, R. L. (1971). Evolution of reciprocal altruism. Quarterly Review of Biology, 46, 35-57. doi:10.1086/406755

Tropp, L. R., \& Pettigrew, T. F. (2005). Relationships between intergroup contact and prejudice among minority and majority status groups. Psychological Science, 16, 951-957. doi:10.1111/j.1467-9280.2005.01643.x

Turner, R. N., Crisp, R. J., \& Lambert, E. (2007). Imagining intergroup contact can improve intergroup attitudes. Group Processes \& Intergroup Relations, 10, 427-441. doi:10.1177/1368430207081533

Urban, L. M., \& Miller, N. (1998). A theoretical analysis of crossed categorization effects: A meta-analysis. Journal of Personality and Social Psychology, 74, 894-908. doi:10.1037//0022-3514.74.4.894

Valley, K. L., Neale, M. A., \& Mannix, E. A. (1995). Friends, lovers, colleagues, strangers: The effects of relationships on the process and outcome of dyadic negotiations. Research on Negotiation in Organizations, 5, 65-94.

Van Lange, P., Liebrand, W. B. G., Messick, D. M., \& Wilke, H. A. M. (1992). Social dilemmas: The state of the art introduction and literature review. In W. B. G. Liebrand, D. M. Messick, \& H. A. M. Wilke (Eds.), Social dilemmas: Theoretical issues and research findings (pp. 3-28). Elmsford, NY: Pergamon Press.

Vittengl, J. R., \& Holt, C. S. (2000). Getting acquainted: The relationship of self-disclosure and social attraction to positive affect. Journal of Social and Personal Relationships, 17, 53-66. doi:10.1177/0265407500171003

Wade-Benzoni, K. A., Tenbrunsel, A. E., \& Bazerman, M. H. (1996). Egocentric interpretations of fairness in asymmetric, environmental social dilemmas: Explaining harvesting behavior and the role of communication. Organizational Behavior and Human Decision Processes, 67, 111-126. doi:10.1006/obhd.1996.0068

Walton, R. E., \& McKersie, R. B. (1965). A behavioral theory of labor relations. New York, NY: McGraw-Hill.

Watson, D., Clark, L. A., \& Tellegen, A. (1988). Development and validation of brief measures of positive and negative affect: The PANAS scales. Journal of Personality and Social Psychology, 54, 1063-1070. doi:10.1037// 0022-3514.54.6.1063

Weber, J. M., Kopelman, S., \& Messick, D. M. (2004). A conceptual review of decision making in social dilemmas: Applying a logic of appropriateness. Personality and Social Psychology Review, 8, 281-307. doi:10.1207/ s15327957pspr0803_4

Ybarra, O. (2002). Naive causal understanding of valenced behaviors and its implications for social information processing. Psychological Bulletin, 128, 421-441. doi:10.1037//0033-2909.128.3.421

Ybarra, O., Keller, M. C., Chan, E., Garcia, S. M., Sanchez-Burks, J., Rios Morrison, K., et al. (2010). Being unpredictable: Friend or foe matters. Social Psychological and Personality Science, 1, 259-267. doi:10.1177/ 1948550610370214

David S. Lee is a Ph.D. student in social psychology at the University of Michigan. He is interested in the role of social processes in various outcomes such as decision-making, motivation, and well-being. 
Scott J. Moeller is an assistant professor of psychiatry and neuroscience at the Icahn School of Medicine at Mount Sinai. His research of decision-making focuses on how extreme desires, such as craving for addictive drugs, influence preferences. He received his Ph.D. from the University of Michigan.

Shirli Kopelman is a leading researcher, expert, and educator in the field of negotiations at the University of Michigan's Ross School of Business and the Ford School of Public Policy. She holds a Ph.D. in management and organizations and an MS in organization behavior from the Kellogg School of Management at Northwestern University. Her research on emotions in negotiations and social dilemmas has been published in scholarly journals, including Organizational Behavior and Human Decision Processes, Journal of Applied Psychology, and Negotiation and Conflict Management Research. Her work has been featured in media outlets such as Bloomberg Businessweek, Forbes, and Harvard Business Review. Shirli Kopelman is the author of Negotiating Genuinely: Being Yourself in Business, published in 2014 by Stanford University Press.

Oscar Ybarra is a professor of psychology at the University of Michigan. His research examines how social factors (interpersonal, group, organizational) influence general cognition, decision-making, and behavioral flexibility and creativity. 